\title{
Brief
}

\section{Early failure of a mechanical bileaflet aortic valve prosthesis due to pannus: A rare complication}

\author{
Markus Kondruweit, MD, ${ }^{a}$ Frank A. Flachskampf, MD, ${ }^{\mathrm{b}}$ Michael Weyand, MD, ${ }^{\mathrm{a}}$ Joachim Schmidt, MD, \\ Stephan Achenbach, MD, and Thomas Strecker, MD, ${ }^{\mathrm{b}}$ Erlangen-Nuremberg, Germany
}

Video clip is available online.

From the Center of Cardiac Surgery, Department of Cardiology, ${ }^{\mathrm{b}}$ and Department of Anesthesiology, ${ }^{c}$ FriedrichAlexander-University, Erlangen-Nuremberg, Germany.

Received for publication Dec 19, 2007; revisions received Dec 28, 2007; accepted for publication Jan 7, 2008.

Address for reprints: Thomas Strecker, MD, Center of Cardiac Surgery, FriedrichAlexander-University Erlangen-Nuremberg, Krankenhausstrasse 12, 91054 Erlangen, Germany (E-mail: thomas.strecker@ukerlangen.de).

J Thorac Cardiovasc Surg 2008;136:213-4 0022-5223/\$34.00

Copyright $\odot 2008$ by The American Association for Thoracic Surgery

doi:10.1016/j.jtcvs.2008.01.008

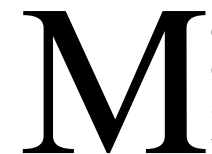

echanical valvular prostheses have the advantage of long-lived duration. Most common reasons for failure are thrombosis or pannus, which can lead to a blockade of the valve. Thrombotic complications are most common early postoperatively, whereas pannus occurs later, especially in bileaflet valves in the aortic position. We report a case in which a bileaflet mechanical valve in the aortic position failed owing to early pannus formation that led to a reoperation.

\section{Clinical Summary}

In February 2007, we performed an aortic valve replacement with a bileaflet mechanical valve prosthesis in a 53-year-old woman with severe aortic valve stenosis. The patient had already received a mechanical bileaflet mitral valve prosthesis because of mitral valve stenosis caused by rheumatic fever in 1987. This valve was functioning well. The cardiovascular risk profile showed no further factors other than hypertension. Because of the small build of the patient, it was possible to implant only a 19-mm St Jude Medical bileaflet mechanical valve (St Jude Medical, Inc, St Paul, Minn). This valve was efficient because of the small body surface of the patient $\left(1.52 \mathrm{~m}^{2}\right)$. We used a noneverting interrupted suture technique for implanting the valve. The early postoperative course was uneventful and the echocardiographic postoperative evaluation showed that both the aortic and mitral valve prostheses were working properly. The patient was discharged to her home in a good condition.

She was readmitted to our center because of severe dyspnea and reduced exercise capacity in August 2007. Echocardiography now showed a blockade of one of the leaflets of the mechanical aortic valve prosthesis, with a high transprosthetic gradient (maximal gradient $98 \mathrm{~mm} \mathrm{Hg}$, mean gradient $66 \mathrm{~mm} \mathrm{Hg}$; Figure 1), which was confirmed on fluoroscopy (Data Supplement Movie E1) and 64-slice spiral computed tomography (Data Supplement Movie E2). The mitral valve prosthesis still was properly working. Therefore, reoperation was performed. Intraoperatively, the reason for the failure of the valve was found to be pannus formation, which led to a blockade of one of the leaflets (Figure 2). The pannus was dissected, and after cleaning and testing of the leaflets, the prosthesis was functioning normally. The postoperative echocardiographic examination also showed normal prosthetic function, so that the patient was discharged to her home again. Histologic findings confirmed macroscopic suspicion of pannus formation with cellular connective tissue. There was no endocarditis or malignancy.

\section{Discussion}

The most common complication of mechanical heart valves are thrombus or pannus formation, with the latter usually seen late after surgery. ${ }^{1}$ These complications are infrequent but serious. The incidence of pannus formation in prosthetic heart valves in the aortic position is described as between $0.1 \%$ and $0.6 \%$ per patient per year, ${ }^{1-4}$ and in all cases this occurs at long-term follow-up. The reason for pannus formation is supposed to be a healing reaction of the endocardium, ${ }^{4}$ although a history of rheumatic fever is also discussed as a risk factor. ${ }^{1}$

In our case, there are two uncommon circumstances: (1) the early development of pannus formation and (2) its development at the aortic valve prosthesis rather than at the mitral valve mechanical prosthesis, which had been in place much longer. The reason could be the small size 


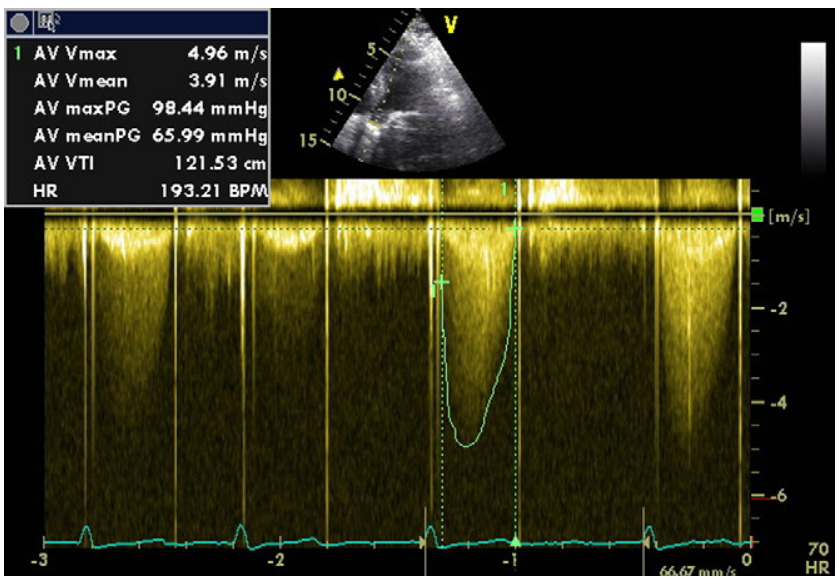

Figure 1. Echocardiography: Increased systolic transaortic prosthetic gradients (maximal gradient $98 \mathrm{~mm} \mathrm{Hg}$, mean gradient 66 $\mathrm{mm} \mathrm{Hg}$ ) by continuous Doppler sonography. AV, Aortic valve; Vmax, maximum velocity; PG, prosthetic gradient; VTI, velocitytime integral; $H R$, heart rate.

of the aortic valve bed, facilitating obstruction even with a relatively small amount of thrombus, whereas the bigger diameter of the mitral valve prosthesis protected it from pannus formation blockade.

In conclusion, prosthetic valve dysfunction in the aortic position resulting from pannus formation 6 months after surgery is very uncommon but is possible in patients with a small heart valve prosthesis and a history of rheumatic fever.

\section{References}

1. Rizzoli G, Guglielmi C, Toscano G, Pistorio V, Vendramin I, Bottio T, et al. Reoperations for acute prosthetic thrombosis and pannus: an assess-

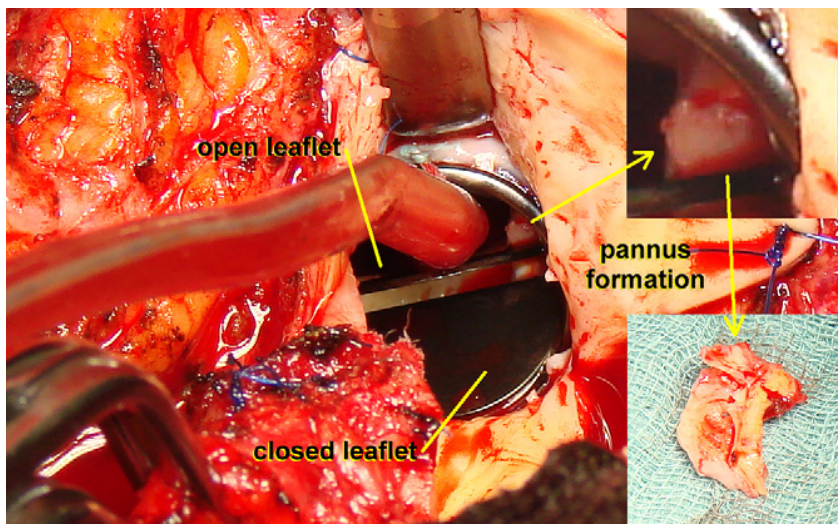

Figure 2. Intraoperative photograph showing the resected pannus formation attached to one of the leaflets of the mechanical aortic valve prothesis.

ment of rates, relationship and risk. Eur J Cardiothorac Surg. 1999;16: 74-80.

2. DeWall RA, Schuster B, Hicks G Jr, Pelletier C, Bonan R, Martineau JP, et al. Seventy-six month experience with the Omniscience cardiac valve. J Cardiovasc Surg (Torino). 1987;28:328-32.

3. Bortolotti U, Milano A, Mossuto E, Mazzaro E, Thiene G, Casarotto D. Early and late outcome after reoperation for prosthetic valve dysfunction: analysis of 549 patients during a 26-year period. J Heart Valve Dis. 1994; 3:81-7.

4. Teshima H, Hayashida N, Yano H, Nishimi M, Tayama E, Fukunaga S, et al. Obstruction of St Jude Medical valves in the aortic position: histology and immunohistochemistry of pannus. J Thorac Cardiovasc Surg. 2003;126:401-7. 